OPEN ACCESS

Edited by:

Mutamed Ayyash,

United Arab Emirates University,

United Arab Emirates

Reviewed by:

Laurent Dufossé,

Université de la Réunion, France

Zhenqiang $\mathrm{Wu}$,

South China University of Technology,

China

*Correspondence:

Xucong LV

xucong1154@163.com

$\mathrm{LiNi}$

nili-fzu@qq.com

Specialty section:

This article was submitted to

Food Microbiology,

a section of the journal

Frontiers in Microbiology

Received: 26 May 2021

Accepted: 05 July 2021

Published: 02 August 2021

Citation:

Wu L, Zhou K, Chen F, Chen G, Yu Y, LV X, Zhang W, Rao P and Ni L

(2021) Comparative Study on the Antioxidant Activity of Monascus Yellow Pigments From Two Different

Types of Hongqu-Functional Qu

and Coloring Qu.

Front. Microbiol. 12:715295.

doi: 10.3389/fmicb.2021.715295

\section{Comparative Study on the Antioxidant Activity of Monascus Yellow Pigments From Two Different Types of Hongqu-Functional Qu and Coloring Qu}

\author{
Li Wu ${ }^{1,2,3}$, Kangxi Zhou ${ }^{2}$, Feng Chen ${ }^{2}$, Guimei Chen², Ying Yü ${ }^{2}$, Xucong Lv ${ }^{1,2 *}$, \\ Wen Zhang ${ }^{2}$, Pingfan $\mathrm{RaO}^{2}$ and $\mathrm{Li} \mathrm{Ni}^{1,2 *}$
}

\begin{abstract}
${ }^{1}$ College of Chemistry, Fuzhou University, Fuzhou, China, ${ }^{2}$ Institute of Food Science and Technology, College of Biological Science and Engineering, Fuzhou University, Fuzhou, China, ${ }^{3}$ Research Institute of Agri-Engineering and Technology, Fujian Academy of Agricultural Sciences, Fuzhou, China
\end{abstract}

This study is the first to investigate the difference in the composition of Monascus azaphilone pigments (MonAzPs) between functional $\mathrm{Qu}(\mathrm{FQ})$ and coloring $\mathrm{Qu}(\mathrm{CQ})$ and analyze their relationships with antioxidant activity. The composition of key active components and antioxidant activity of the ethanol extracts of $F Q$ and $C Q$ were analyzed by Uv-vis, HPLC, and chemical antioxidant tests. The composition of MonAzPs of the ethanol extracts was further analyzed by HPLC-MS. Seven Monascus yellow pigments (MYPs) with high abundance were successfully purified for the antioxidation evaluation in vitro and in the cell. Correlation analysis between the metabolites and the antioxidant activity of Hongqu indicated that MonAzPs might play an essential role in the antioxidant activity $(r>0.80)$. By contrast, the monacolin $\mathrm{K}(\mathrm{MK})$, polysaccharide, ergosterol, and $\gamma$-aminobutyric acid (GABA) were not significantly correlated with the antioxidant activity. Orthogonal partial least squares discriminant analysis (OPLS-DA) based on the composition of MonAzPs revealed that the abundance of MYPs is significantly different between FQ and $C Q(P<0.05$ and VIP $>1.0)$. Seven MYPs (monasfluore A, monaphilone $\mathrm{B}$, monascuspilion, monascin, monaphilone $\mathrm{A}$, ankaflavin, and new yellow pigment) with high abundance were successfully purified for the antioxidation evaluation. Chemical antioxidant tests revealed that the antioxidant activities of monaphilone $A$, ankaflavin, and new yellow pigment only from $C Q$ were significantly more potent than monasfluore A and monascuspilion only separated from FQ. The cellular antioxidant assay (CAA) showed that the new yellow pigment had the best antioxidant activity (quercetin equivalent 7.23 $\mu \mathrm{M}$ ), followed by monasfluore $A$ and monaphilone $B$, all of which were significantly better than monascin and ankaflavin, the two most frequently reported MYPs. Research on the structure-activity relationship demonstrated that alterations of the hydroxyl that occurred on C-3' or C-11 obviously affected the 


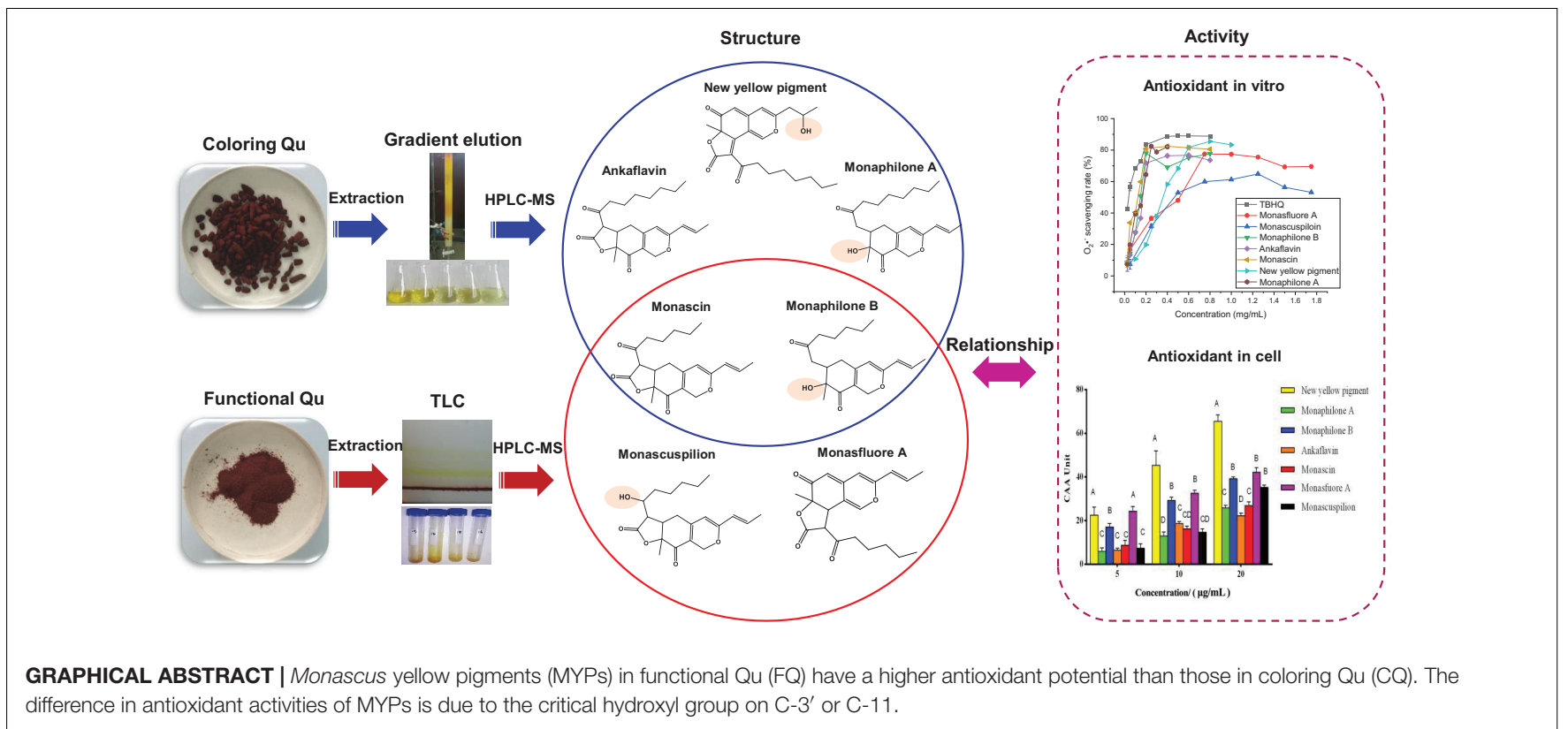

antioxidant activities of MYPs. Our findings provide evidence that MYPs may be the key active components for $\mathrm{CQ}$ to have a more potent antioxidant capacity than $\mathrm{FQ}$. The alterations of the hydroxyl that occurred on C-3' or C-11 obviously affected the antioxidant activities of MYPs.

Keywords: Hongqu, Monascus azaphilone pigments, Monascus yellow pigment, antioxidant activity, cellular antioxidation

\section{INTRODUCTION}

Hongqu (rice fermented by Monascus) is used as medicine and food for thousands of years in Asia (Huang Z. et al., 2019). According to the different Monascus strains (Monascus pilosus for FQ and Monascus purpureus for CQ) and fermentation processes (Supplementary Figure 1), Hongqu is mainly divided into functional $\mathrm{Qu}(\mathrm{FQ})$ and coloring $\mathrm{Qu}(\mathrm{CQ})$. FQ is rich in Monacolin K (MK, over $4.0 \mathrm{mg} / \mathrm{g}$ )(National Development and Reform Commission of the People's Republic of China, 2007), and CQ is rich in Monascus Azaphilone pigments (MonAzPs, over $1000 \mathrm{U} / \mathrm{g}$ )(National Health and Family Planning Commission of the People's Republic of China, 2015). FQ and CQ are fermented with different Monascus strains with excellent pigment and MK production ability, respectively. Besides, CQ is generally fermented in a large pond for 57 days, and FQ is generally fermented in an Erlenmeyer flask (500 or $1,000 \mathrm{ml}$ ) for $35-42$ days. Because of the differences in the fermentation strains and fermentation processes, the fermented products (FQ and $\mathrm{CQ}$ ) have different metabolite compositions and functional characteristics. The ancient medical work "Compendium of Materia Medica" recorded that Hongqu has the beneficial effects of promoting blood circulation and removing blood stasis. Modern medical researches verified and explored multiple pharmacological activities of Hongqu and its metabolites, including hypolipidemia (Wang and Pan, 2003; Lee and Pan, 2012; Lee C. L. et al., 2013), hypoglycemia (Shi et al., 2012; Zhou et al., 2019), and anti-aging (Chen et al., 2015). Certain correlations between those pharmacological activities and antioxidation had been found with the in-depth study. The mechanism may be related to that special molecular structure transferring hydrogen to free radicals or accepting free radical electrons (Zhang et al., 2020), which can scavenge excessive free radicals and maintain redox balance. The study of antioxidant activity has been the basis for other activities. The antioxidant activity of Hongqu may be related to the key active components of Monascus, including MonAzPs, MK, $\gamma$-aminobutyric acid (GABA), ergosterol, and polysaccharides. However, the effects or contribution of the metabolites in Hongqu on the antioxidant activity needs to be further evaluated.

Among the metabolites in Hongqu, MonAzPs have excellent antioxidant capacity (Qu et al., 2008; Chen et al., 2017), of which MYPs have the most potent antioxidant capacity (Zhang et al., 2020). A previous study found that ANKASCIN 568 plus (monascin and ankaflavin as the main functional components) may increase the antioxidant enzyme activities and inhibit the oxidation reaction induced by amyloid $A \beta$, thereby significantly improving the memory and learning ability of Alzheimer's (Chen et al., 2015). Besides, monascin may inhibit the oxidative stress caused by the phosphorylation of peroxisome proliferator-activated receptor- $\gamma$ (PPAR $\gamma)$ by attenuating the activation of protein kinase C (PKC), 
thereby repairing pancreatic damage (Hsu W. $H$. et al., 2013). The antioxidant activity has been further confirmed to be closely related to other pharmacological activities (Lee C. L. et al., 2013). The relationship between MonAzPs (especially MYPs) and antioxidant activity needs to be further explored to promote the development and utilization of MYPs antioxidant resources.

In this study, the difference of key active components in Hongqu (FQ and CQ) and their relationship with antioxidant activity were compared. Besides, the composition of MonAzPs and the in vitro antioxidant activity (chemical antioxidant tests and cellular antioxidant assay) of MYPs isolated from two types of Hongqu were further investigated. Finally, the relationship between the antioxidant activities and the structure of MYPs was also analyzed, which laid the foundation for the research on the antioxidant activity of MYPs and also provided a reference for studying the antioxidative related effects of MYPs.

\section{MATERIALS AND METHODS}

\section{Material}

Hongqu samples were mainly collected from Ningde City and Fuzhou City in Fujian Province, and Jinhua City and Jiangshan City in Zhejiang Province, including five samples with MK over
$4.0 \mathrm{mg} / \mathrm{g}$ (also named functional Qu, FQ1-5) and six samples with pigment over 1,000 U/g (also named coloring Qu, CQ1-6) (Table 1). The appearance of Hongqu showed that the shape of FQ was powder and CQ was rice grains, and the color of CQ was redder and darker than FQ (Figure 1).

\section{Analysis of the Composition of Key Active Components}

\section{Determination of the Total Color Value}

The pigments quantification was done with a UV-vis spectrophotometer (CLARIOstar, BMG LABTECH GmbH, Ortenberg, Germany). The total color value was assessed by measuring the absorbance of $75 \%$ ethanol extract of Hongqu at $505 \mathrm{~nm}$. The result was expressed as the absorbance unit per gram at a specific wavelength (Srianta et al., 2016).

\section{Determination of MK by HPLC}

Determination of MK by HPLC was in accordance to the method in QB/T 2847-2007 and reference (Huang C. F. et al., 2019) with minor modification. Before chromatographic analysis, the supernatant was filtered through a $0.22 \mu \mathrm{m}$ filter. The supernatant was measured by Waters e2695 with a chromatographic column (Zorbax SB-C18 column, $5 \mu \mathrm{m} \times 250 \mathrm{~mm} \times 4.6 \mathrm{~mm})$ and a UV detector at $238 \mathrm{~nm}$. The mobile phase was composed of methanol:water:phosphoric

TABLE 1 | The source and region of Hongqu.

\begin{tabular}{lccc}
\hline Hongqu & Source & Region & Remarks \\
\hline FQ1 & Zhejiang Sanhe Biotech Co., Ltd. & Jiangshan City, Zhejiang Province & MK 3.0\% \\
FQ2 & Zhejiang Sanhe Biotech Co., Ltd. & Jiangshan City, Zhejiang Province & Jinhua City, Zhejiang Province \\
FQ3 & Fuzhou University & Fuzhou City, Fujian Province & MK 0.5\% \\
FQ4 & Fujian Outlet Biotech Co., Ltd. & Fuzhou City, Fujian Province & MK0.5\% \\
FQ5 & Fujian Outlet Biotech Co., Ltd. & Ningde City, Fujian Province & MK 1.0\% \\
CQ1 & Fujian Pinghuhong Bio-tech Co., Ltd. & Ningde City, Fujian Province & Color value 1,000 U/g \\
CQ2 & Fujian Chengjiu Hongqu Co., Ltd. & Ningde City, Fujian Province & Color value 1,300 U/g \\
CQ3 & Fujian Pinghuhong Bio-tech Co., Ltd. & Ningde City, Fujian Province & Color value 2,000 U/g \\
CQ4 & Fujian Pinghuhong Bio-tech Co., Ltd. & Ningde City, Fujian Province & Color value 4,000 U/g \\
CQ5 & Fujian Chengjiu Hongqu Co., Ltd. & Ningde City, Fujian Province & Color value 500 U/g \\
CQ6 & Fujian Chengjiu Hongqu Co., Ltd. & & Color value 3,500 U/g
\end{tabular}

FIGURE 1| Appearance of Hongqu. FQ1-FQ5 were functional $\mathrm{Qu}$ (FQ). CQ1-CQ6 were coloring Qu (CQ).


acid in a ratio of 385:115:0.14 (v/v), with an accompanying flow rate of $1.0 \mathrm{ml} / \mathrm{min}$.

\section{Determination of $\gamma$-Aminobutyric Acid by HPLC}

$\gamma$-Aminobutyric acid was extracted and analyzed according to the method in QB/T 4587-2013 (Ministry of Industry and Information Technology of the People's Republic of China, 2013). The content of GABA was determined by HPLC equipped with a reversed-phase column (Novapack C18, $300 \mathrm{~mm} \times 3.9 \mathrm{~mm} \times 4 \mu \mathrm{m}$, Waters, Milford, MA, United States). Eluted GABA was detected at $280 \mathrm{~nm}$ and expressed as $\mathrm{mg} / 100 \mathrm{~g}$ dry Hongqu (Garzón et al., 2020).

\section{Determination of Ergosterol by HPLC}

The content of ergosterol was determined by HPLC equipped with an ODS18 column $(250 \mathrm{~mm} \times 4.6 \mathrm{~mm} \times 5 \mu \mathrm{m}$, Waters, Milford, MA, United States) at $280 \mathrm{~nm}$. Ergosterol in Hongqu was identified by a combination of the retention time in HPLC chromatograms with standards (Guan et al., 2016).

\section{Determination of Polysaccharides by HPLC}

The preparation of Hongqu polysaccharides was under the method in the literature (Xie et al., 2012). The polysaccharide was detected by the phenol-sulfuric acid method (Dubois et al., 1956).

\section{Composition of MonAzPs}

Determination of pigment compounds was in accordance to the method (Liang et al., 2019) with some modifications. The analysis was conducted by Agilent 2000 HPLC system (Agilent Technologies, Santa Clara, CA, United States) comprised of a binary pump, an autosampler, and a thermostatically controlled column compartment. Pigments were separated on a $250 \times 4.6 \mathrm{~mm}$ ODS1 8 column $(5 \mu \mathrm{m}$, Waters, Milford, MA, United States) with a linear gradient of the mobile phase of solvent A (water, containing $0.1 \%$ formic acid, $\mathrm{v} / \mathrm{v}$ ) and solvent B (acetonitrile), a flow rate of $1.0 \mathrm{ml} / \mathrm{min}$, oven temperature of $35^{\circ} \mathrm{C}$, and run time for $55 \mathrm{~min}$. Mass spectrometry was operated with a 6520 QTOF-MS (Agilent Technologies, Santa Clara, CA, United States) equipped with an ESI source. The parameters of the ESI source were set as follows: capillary voltage, 3,500 V; fragmentor voltage, $135 \mathrm{~V}$; drying gas (N2) temperature, $350^{\circ} \mathrm{C}$; drying gas $\left(\mathrm{N}_{2}\right)$ flow rate, $10.0 \mathrm{~L} / \mathrm{min}$; nebulizer gas pressure, 30 psig; OCT RF V, $750 \mathrm{~V}$; skimmer voltage, $65 \mathrm{~V}$. Each sample was analyzed in positive modes with a mass scan range of $\mathrm{m} / \mathrm{z} 50$ 1,200 Da, and collision energy (CE) was set as 15 and $30 \mathrm{eV}$. Data acquisition and analysis were operated by Agilent LC/MS Qualitative Analysis Software (version B.04.00).

\section{Antioxidant Activity of Hongqu and MYPs in vitro \\ DPPH Free Radical Scavenging Experiment}

The DPPH radical scavenging capacity was determined according to the method described by reference (Brand Williams et al., $1995)$ with minor modification. Each sample with a fixed volume of $1.0 \mathrm{ml}$ was mixed with $1.0 \mathrm{ml} \mathrm{DPPH}$ solution $(0.2 \mathrm{mM}$ in anhydrous ethanol) stored in the dark at room temperature for $30 \mathrm{~min}$. Then, its absorbance $A_{i}$ was measured at $517 \mathrm{~nm}$ using a microplate reader (CLARIOstar, BMG LABTECH GmbH, Ortenberg, Germany). At the same time, the absorbance $\mathrm{A}_{c}$ of the mixture of DPPH solution and an equal volume of anhydrous ethanol and the absorbance $\mathrm{A}_{j}$ of the mixture of the sample solution and the equal volume of anhydrous ethanol were determined at $517 \mathrm{~nm}$. The DPPH radical scavenging activity was expressed as the percentage of inhibition of DPPH according to the following formula. Inhibition rate of DPPH $=\left[1-\left(\mathrm{A}_{\mathrm{i}^{-}}\right.\right.$ $\left.\left.\mathrm{A}_{j}\right) / \mathrm{A}_{c}\right] \times 100 \%$.

\section{ABTS Free Radical Scavenging Experiment}

ABTS radical scavenging ability was determined according to the method with some modifications (Sridhar and Charles, 2019). The ABTS ${ }^{+}$working solution was produced by reacting the ABTS. ${ }^{+}$stock solution $\left(7.4 \mathrm{mM}\right.$ ABTS) with the $\mathrm{K}_{2} \mathrm{~S}_{2} \mathrm{O}_{8}$ stock solution $\left(2.6 \mathrm{mM} \mathrm{K} \mathrm{S}_{2} \mathrm{O}_{8}\right)$ in equal quantities and allowed them to react for $12-16 \mathrm{~h}$ at room temperature in the dark and diluting with anhydrous ethanol to make its absorbance $0.70 \pm 0.02$ at $734 \mathrm{~nm}$. ABTS. ${ }^{+}$working solution $(1.0 \mathrm{ml})$ was mixed with $0.25 \mathrm{ml}$ of the ethanol extract of Hongqu or standard (dibutyl hydroxytoluene, BHT) at different concentrations (0.1$10 \mu \mathrm{g} / \mathrm{ml}$ ). The mixture was incubated at room temperature for exactly $10 \mathrm{~min}$ in the dark and determined the absorbance at $734 \mathrm{~nm}(\mathrm{~A})$. The control $\left(\mathrm{A}_{0}\right)$ was prepared by mixing $1.0 \mathrm{ml}$ of ABTS. ${ }^{+}$solution with $0.25 \mathrm{ml}$ of anhydrous ethanol. The percentage results of scavenging activity were calculated as inhibition rate using the following equation. Inhibition rate of ABTS. ${ }^{+}=\left[\left(\mathrm{A}_{0}-\mathrm{A}\right) / \mathrm{A}_{0}\right] \times 100 \%$.

\section{Ferrous-Reducing Power}

Ferrous-reducing power was determined as described in the literature (Eda et al., 2016) with some modifications. Sample solution $(0.25 \mathrm{ml})$, phosphate buffer $(0.25 \mathrm{ml})(\mathrm{pH} 6.6,0.2 \mathrm{~mol} / \mathrm{L})$, and potassium ferricyanide $(0.25 \mathrm{ml})(10 \mathrm{~g} / \mathrm{L})$ were placed in a $1.5 \mathrm{ml}$ centrifuge tube. After incubation at $50^{\circ} \mathrm{C}$ for $20 \mathrm{~min}$ and cooling to room temperature, $0.25 \mathrm{ml}$ of $10 \%(\mathrm{~m} / \mathrm{v})$ trichloroacetic acid (TCA) solution was added and centrifuged at $4{ }^{\circ} \mathrm{C}$ and $10,000 \mathrm{r} / \mathrm{min}$ for $15 \mathrm{~min}$. Supernatant $(0.5 \mathrm{ml})$, distilled water $(0.5 \mathrm{ml})$, and $0.1 \%(\mathrm{~m} / \mathrm{v})$ ferric chloride solution $(0.1 \mathrm{ml})$ were added and reacted for $10 \mathrm{~min}$. The absorption was measured at $700 \mathrm{~nm}$.

\section{Superoxide Anion Free Radical Scavenging Experiment}

The superoxide anion was produced by the AP-TEMED system and reacted with hydroxylamine hydrochloride to form $\mathrm{NO}_{2}{ }^{-}$. Then, $\mathrm{NO}_{2}{ }^{-}$was reacted with paminobenzenesulfonic acid and $\alpha$-naphthylamine to form a red azo compound with a characteristic absorption peak at $530 \mathrm{~nm}$ (Takei et al., 2017). The scavenging ability of oxygen anions was negatively correlated with the absorbance at $530 \mathrm{~nm}$. $\mathrm{O}^{2-}$ radical-scavenging activity was measured by a non-enzymatic method with a test kit produced by Beijing Solarbio Science and Technology Co., Ltd.

\section{Determination of the Inhibition Rate of Yolk Lipoprotein (AOA\%)}

The inhibition rate of yolk lipoprotein (AOA\%) was determined as described in our previous report (Wu et al., 2016). Phosphoric 
acid buffer $(3.0 \mathrm{ml})(0.1 \mathrm{~mol} / \mathrm{L}), 1: 25$ yolk suspension $(0.4 \mathrm{ml})$, $\mathrm{FeSO}_{4}$ solution $(0.2 \mathrm{ml})(25 \mathrm{mmol} / \mathrm{L})$, and sample solution $(0.2 \mathrm{ml})$ were placed in $10 \mathrm{ml}$ tubes, respectively. The control tube $\left(\mathrm{A}_{0}\right)$ was placed with $0.2 \mathrm{ml}$ of phosphoric acid buffer instead of the sample solution (A). After incubation at $37^{\circ} \mathrm{C}$ for $12 \mathrm{~h}, 1.0 \mathrm{ml}$ of $20 \%$ trichloroacetic acid was added, centrifuging for $10 \mathrm{~min}$ at $3,500 \mathrm{r} / \mathrm{min}$. Supernatant $(4.0 \mathrm{ml})$ was reacted with $2.0 \mathrm{ml}$ of $0.8 \%$ thiobarbituric acid solution for $15 \mathrm{~min}$ at $100^{\circ} \mathrm{C}$. The absorbance was determined at $532 \mathrm{~nm}$ and calculated by the following formula, Yolk lipoprotein inhibition rate $(\mathrm{AOA} \%)=\left[\left(\mathrm{A}_{0}-\mathrm{A}\right) / \mathrm{A}_{0}\right] \times 100$.

\section{Determination of the Cellular Antioxidant Activity of MYPs}

Cellular antioxidant measurements were determined following the method (Wolfe and Liu, 2007) with modifications. Caco-2 cells in the logarithmic growth phase were inoculated into 96 well cell culture plates at the density of $6 \times 10^{4}$ cells/well. The growth medium was removed, and the cells were washed with HBS to remove any non-adherent and dead cells. Next, $50 \mu \mathrm{l} \mathrm{DCFH-}$ DA working solution $(25 \mu \mathrm{M})$ was added to each well, followed by $50 \mu \mathrm{l}$ of the sample solution (in triplicate wells). For positive control, $50 \mu \mathrm{l}$ of quercetin (the final dilution concentration was 2 , $4,6,8$, and $10 \mu \mathrm{M}$ ) were applied in triplicate wells, while the blank group was treated with DCFH-DA without ABAP. Once the DCFH-DA and antioxidant treatments were added, the cells were placed in the incubator for $1.0 \mathrm{~h}$ at $37^{\circ} \mathrm{C}$. After this period, the cells were washed with HBS, and DCFH-DA was removed. Then, each well was added with $100 \mu$ l ABAP $(600 \mu \mathrm{M})$. The cells were immediately placed in a FlexStation 3 multifunctional calcium flow detection workstation (Molecular devices, United States), where real-time fluorescence was read initially and every $5 \mathrm{~min}$, then after for $1.0 \mathrm{~h}$. Fluorescence was measured at an excitation wavelength of $485 \mathrm{~nm}$ and an emission wavelength of $538 \mathrm{~nm}$ (Zhou et al., 2020).

The formula was as follows : CAA unit $=\%$ reduction

$$
=100-\left(\int \mathrm{SA}-\int \mathrm{CA}\right) \times 100
$$

where $\int \mathrm{SA}$ was the integrated area under the sample fluorescence vs. time curve and $\int \mathrm{CA}$ was the integrated area from the control curve.

\section{Isolation of MYPs From Crude Extracts of $F Q$ and $C Q$}

Coloring Qu sample was prepared according to $0.1 \mathrm{~g} / \mathrm{ml} \mathrm{CQ}$ ethanol extracts: $200-300$ mesh silica gel $=2: 1(\mathrm{v} / \mathrm{m})$, mixed and dried at $50^{\circ} \mathrm{C}$ for $48 \mathrm{~h}$. Then, CQ sample was located on a silica gel column and eluent with the solvent of n-hexane/ethyl acetate $(5: 1, \mathrm{v} / \mathrm{v})$ to yield yellow pigments. The similar fractions were combined into five main fractions according to OD $410 \mathrm{~nm}$ and 300-600 nm scan, and the solvent was removed under reduced pressure. The ethyl acetate phase of the FQ sample was prepared and repeated three times according to the rate of $0.1 \mathrm{~g} / \mathrm{ml}$ FQ ethanol extracts:ethyl acetate:double distilled water $=1: 2: 3$ in a $500 \mathrm{ml}$ separating funnel and isolated by
TLC (developing solvent was n-hexane:ethyl acetate:petroleum ether $=30: 17: 8$ ), The band with the same $\mathrm{R}_{\mathrm{f}}$ (drew under UV $365 \mathrm{~nm}$ light) was collected. These resultant fractions were further analyzed by HPLC, and then fractions with the same retention time were combined, and the solvent was removed under reduced pressure. The obtained seven yellow pigments, namely, monaphilone $\mathrm{B}$, monascin, monascuspilion, monasfluore $\mathrm{A}$, new yellow pigment, monaphilone $\mathrm{A}$, and ankaflavin, were dissolved in ethanol for HPLC-QTOF-MS analysis and antioxidative activity determination. The HPLC diagram, mass spectrum, and structure diagram of MYPs were shown in Supplementary Figures 2-8.

\section{Statistical Analysis}

The measurement data were expressed as mean value \pm standard deviation (mean \pm SD). Single-factor variance analysis and spearman's correlations coefficient were calculated by using SPSS 22.0 (SPSS Inc., United States). Bioplot diagram, permutation test diagram of orthogonal partial least squares discriminant analysis (OPLS-DA), VIP diagram, and HCA diagram were drawn using the SIMCA-14.1 (UMETRICS, Sweden) based on the relative abundance of MonAzPs determined with HPLC-MS.

\section{RESULTS AND DISCUSSION}

\section{Analysis of the Composition of Key Active Components of $F Q$ and $C Q$}

\section{The Total Color Value}

According to Figure 2, the units of absorbance at $505 \mathrm{~nm}$ $\left(\mathrm{E}_{505}\right)$ of $\mathrm{CQ}$, indicating the total color value, were extremely significantly higher than those of FQ. The average value of $\mathrm{E}_{505}$ of CQ was approximately 2,569.60 U/g, while that of FQ was only $283.24 \mathrm{U} / \mathrm{g}$. The $\mathrm{E}_{505}$ of CQ was approximately 9.0 times compared with that of FQ. For example, Huang et al. (2017) reported a higher antioxidative potential in a fermented mixture of Radix Puerariae and rice than in that fermented by only Radix Puerariae and rice due to the higher levels of pigments. The total color value of red yeast rice (RYR) and fermented Radix Puerariae and rice (FPR) was 1,300 \pm 25 units/g and $6,164 \pm 799$ units/g, respectively. FPR increased the color value by three times compared with RYR. The result indicated that the total color value between CQ and FQ was different, so the differences in Monascus pigments composition needed to be further analyzed.

\section{MK}

Monacolin $\mathrm{K}$ is one of the well-documented metabolites of Monascus and is recognized as a cholesterol-lowering regent because of its competitive inhibitory effect on 3-hydroxy-3methylglutaryl coenzyme A (HMG-CoA) reductase. The total amount of $\mathrm{MK}$ is composed of the lactone form and the acid form of MK. The content of MK in Hongqu was shown in Table 2. The total contents of MK of FQ 1-FQ 5 were 33.73, 20.27, $6.98,9.02$, and $10.66 \mathrm{mg} / \mathrm{g}$, respectively. So, FQ 1-FQ 5 met the requirements of the light industry standard of the People's Republic of China that the MK of FQ should be over $4.0 \mathrm{mg} / \mathrm{g}$. 


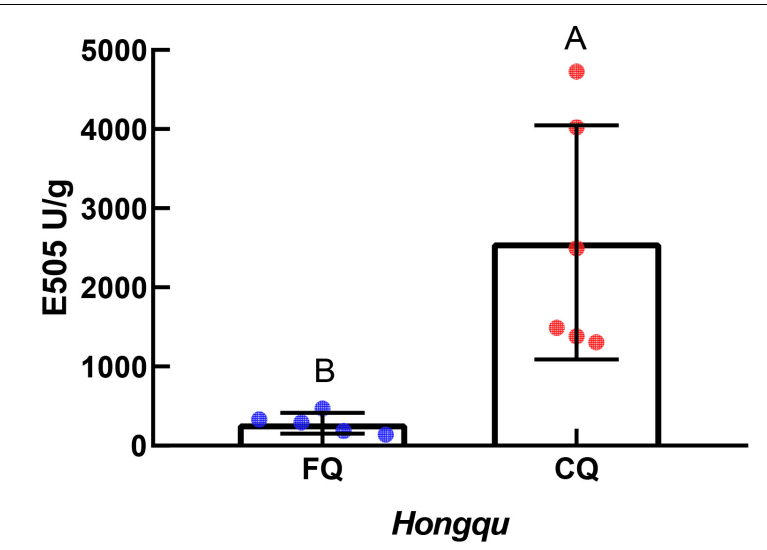

FIGURE 2 | Units of absorbance at $505 \mathrm{~nm}\left(\mathrm{E}_{505}\right)$ of functional Qu (FQ) and coloring $\mathrm{Qu}(\mathrm{CQ})$, respectively.

TABLE 2 | The content of MK in Hongqu (mg/g).

\begin{tabular}{lccc} 
Hongqu & Lactone forms of MK & Acid forms of MK & $\begin{array}{c}\text { The total content } \\
\text { of } \mathbf{M K}\end{array}$ \\
\hline CQ4 & - & $0.26 \pm 0.01$ & $0.26 \pm 0.01$ \\
FQ1 & $29.13 \pm 0.02$ & $4.60 \pm 0.01$ & $33.73 \pm 0.00$ \\
FQ2 & $17.66 \pm 0.08$ & $2.61 \pm 0.02$ & $20.27 \pm 0.11$ \\
FQ3 & $5.11 \pm 0.01$ & $1.88 \pm 0.02$ & $6.98 \pm 0.03$ \\
FQ4 & $7.38 \pm 0.04$ & $1.64 \pm 0.03$ & $9.02 \pm 0.07$ \\
FQ5 & $7.78 \pm 0.04$ & $2.88 \pm 0.01$ & $10.66 \pm 0.05$
\end{tabular}

Use "-" to indicate that it cannot be detected.

The ratios of the active open-hydroxyl acid form and the prodrug lactone form of MK of FQ 1- FQ 5 were 13.64, 12.88, 26.93, 18.18, and $27.02 \%$, respectively. The MK of CQ 4 was the highest among all CQ samples, reaching $0.26 \mathrm{mg} / \mathrm{g}$ (less than the requirements of FQ). Gum et al. (2017) reported higher antioxidant activity in Hongqu fermented Bacillus subtilis than in Hongqu due to the alteration in the physicochemical property of MK.

\section{GABA, Polysaccharides, and Ergosterol}

The contents of GABA, polysaccharide, and ergosterol of CQ were $0.103,14.58$, and $246.92 \mathrm{mg} / \mathrm{g}$, while those of FQ were 0.198 , 35.97 , and $443.65 \mathrm{mg} / \mathrm{g}$, representing increases of 92.23, 146.70, and $79.67 \%$, respectively. The contents of GABA, polysaccharide, and ergosterol of FQ were higher than those of CQ. However, there was no significant difference between them (Figure 3). Lee et al. (2016) reported that amino acids contributed to antioxidant activity in wheat and rice gochujang. Lu et al. (2015) reported that Huangjiu had the highest antioxidant capacity among the three traditional fermented wines (Baijiu, Huangjiu, grape wine) because the amino acid content was $2,923 \mu \mathrm{g} / \mathrm{ml}$, and GABA was $10 \mu \mathrm{g} / \mathrm{ml}$. Numerous studies reported that polysaccharides from different sources and modified products had certain antioxidant activities (Mirzadeh et al., 2020). Liang et al. (2019) reported that the ergosterol in RYR could significantly reduce the levels of total cholesterol, triglycerides, and low-density lipoprotein cholesterol in C57BL/6J mice fed a high-fat diet. Therefore, GABA, polysaccharides, and ergosterol might be potential contributors to antioxidant activity.

\section{In vitro Antioxidant Activity of Ethanol Extracts of $F Q$ and $C Q$}

The ferric ion reducing antioxidant power (FRAP) of $1.0 \mathrm{mg} / \mathrm{ml}$ ethanol extracts of FQ and CQ was measured (Figure 4A). The average FRAP of CQ was 0.645 , which was significantly better than that of FQ (0.301). When the FRAP of $1.0 \mathrm{mg} / \mathrm{ml}$ vitamin C was 0.918 , the FRAP of CQ 4 was the strongest among all samples, reaching 0.702 . Generally, $\mathrm{IC}_{50}$ values were used to reflect the antioxidant capacity of various materials. The $50 \%$ inhibitory concentration $\left(\mathrm{IC}_{50}\right)$ was defined as the concentration of a sample that gave a $50 \%$ inhibition rate. The $\mathrm{IC}_{50}$ value was smaller, and the DPPH radical scavenging activity or ABTS radical scavenging activity was stronger. While the $\mathrm{IC}_{50}$ of $\mathrm{DPPH}$ radical scavenging activity of vitamin $\mathrm{C}$ was $0.023 \mathrm{mg} / \mathrm{ml}$, the average $\mathrm{IC}_{50}$ of $\mathrm{DPPH}$ radical scavenging activity of CQ $(0.176 \mathrm{mg} / \mathrm{ml})$ was significantly lower than that of FQ $(0.544 \mathrm{mg} / \mathrm{ml})$ (Figure 4B). The $\mathrm{IC}_{50}$ of $\mathrm{DPPH}$ radical scavenging activity of CQ 3 was the smallest among all samples, reaching $0.100 \mathrm{mg} / \mathrm{ml}$. While the $\mathrm{IC}_{50}$ of the ABTS radical scavenging activity of vitamin $\mathrm{C}$ was $4.437 \mu \mathrm{g} / \mathrm{ml}$, the average $\mathrm{IC}_{50}$ of ABTS radical scavenging activity of CQ $(28.98 \mu \mathrm{g} / \mathrm{ml})$ was significantly lower than that of FQ $(57.54 \mu \mathrm{g} / \mathrm{ml})$ (Figure $4 \mathrm{C}$ ). The $\mathrm{IC}_{50}$ of CQ 4 was the smallest among all samples, reaching $22.18 \mu \mathrm{g} / \mathrm{ml}$. Gum et al. (2017) reported that the DPPH radical scavenging activity of $2 \mathrm{mg} / \mathrm{ml}$ RYR was approximately $20 \%$, and that of RYR fermented
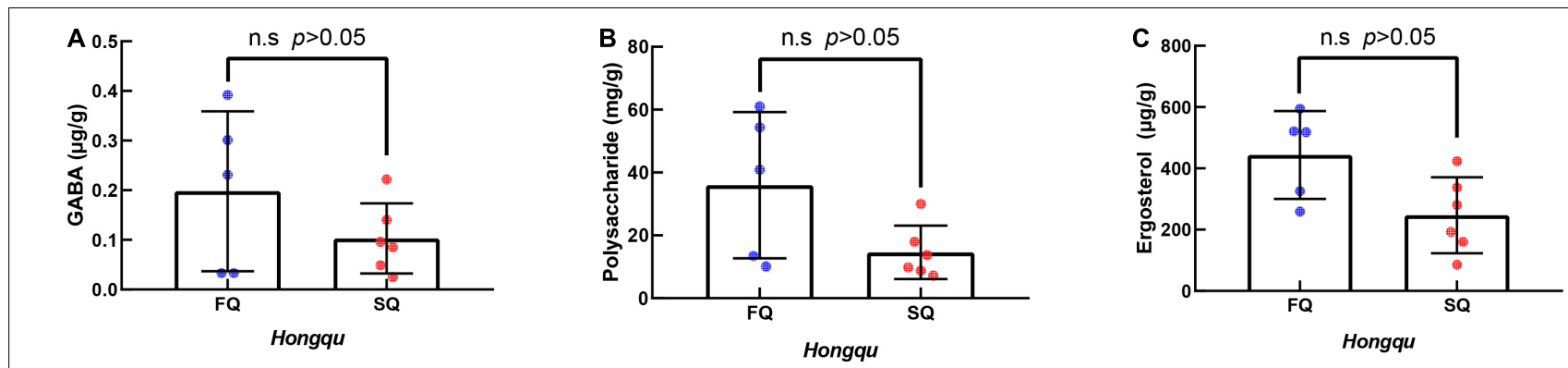

FIGURE 3 | The $\gamma$-aminobutyric acid (GABA), polysaccharides, and ergosterol of functional Qu (FQ) and coloring Qu (CQ), respectively. (A) The $\gamma$-aminobutyric acid. (B) Polysaccharides. (C) Ergosterol. 
with B. subtilis was increased to $70 \%$. The average $\mathrm{IC}_{50}$ of $\mathrm{DPPH}$ radical scavenging activity was $0.100-0.690 \mathrm{mg} / \mathrm{ml}$, which implied that FQ and CQ had a stronger antioxidant activity than those RYR reported previously. Huang et al. (2017) reported higher antioxidant activities in a fermented mixture of Radix Puerariae and rice than RYR due to the three times higher pigment intensity. For example, the DPPH scavenging capacity was $10.58 \mathrm{mg} \mathrm{AEE} / \mathrm{g}$ of the sample, and the FRAP was $0.11 \mathrm{mmol}$ $\mathrm{Fe}^{2+} / \mathrm{g}$ of the sample. Those pieces of literature were very consistent with the stronger antioxidant capacity of CQ than FQ because of the higher color value.

\section{Correlation Analysis Among Key Active Components and Antioxidant Activities of $F Q$ and $C Q$}

Correlation analysis among key active components and antioxidant activities of FQ and CQ was shown in Table 3. There was a strong correlation between the total color value $\left(\mathrm{E}_{505}\right)$ and antioxidant activities. The correlation coefficients of FRAP, $\mathrm{DPPH}, \mathrm{ABTS}$, and $\mathrm{E}_{505}$ were $0.806,0.818$, and 0.822 , respectively. However, there were negative correlations between FRAP and MK $(r=-0.700)$, polysaccharide $(r=-0.091)$, and ergosterol $(r=-0.182)$. DPPH was negatively correlated with ergosterol $(r=-0.427)$, polysaccharide $(r=-0.336)$, MK $(r=-0.200)$, and GABA $(r=-0.046)$. There was a negative correlation between ABTS and MK $(r=-0.500)$. Correlation analysis indicated that MonAzPs played an important role in the antioxidant activities of Hongqu. In contrast, the contents of $\mathrm{MK}$, polysaccharide, ergosterol, and GABA were not significantly correlated with the antioxidant activities of Hongqu. The fermentation of the rice and Radix Puerariae mixture dramatically increased the yields of pigments and significantly improved the antioxidant capacity (Huang et al., 2017).

\section{MonAzPs}

HPLC-QTOF-MS was used to detect the composition of MonAzPs in FQ and CQ. As shown in Table 4 and Figure 5, a total of eighteen different MonAzPs were detected, including eleven yellow pigments (monascin, monaphilone $\mathrm{B}$, ankaflavin, monasfluore $\mathrm{B}$, monasfluore A, FK17-P2B2, monapurfluore, monaphilone A, monascuspilion, monarubrin, and new yellow pigment), two orange pigments (rubropunctatin and monascorubrin), and five red pigments (rubropunctamine, monascorubramine, new red pigment, N-GABA-rubropunctatin, and red pigment). It is worth noting that the chemical composition and the relative abundance of yellow pigments in FQ and CQ were quite different. There were only eight different MonAzPs (five yellow pigments and three red pigments) in FQ (Figure 5A), and the relative abundance of yellow pigments (monascuspilion, monasfluore $\mathrm{A}$, monaphilone $\mathrm{B}$, and monascin) was higher than that of the others. There were seventeen different MonAzPs (eleven yellow pigments, four red pigments, and two orange pigments) in CQ (Figure 5B), and the relative abundance of yellow pigments (monascin, ankaflavin, and monaphilone A) was greater than that of other MonAzPs.
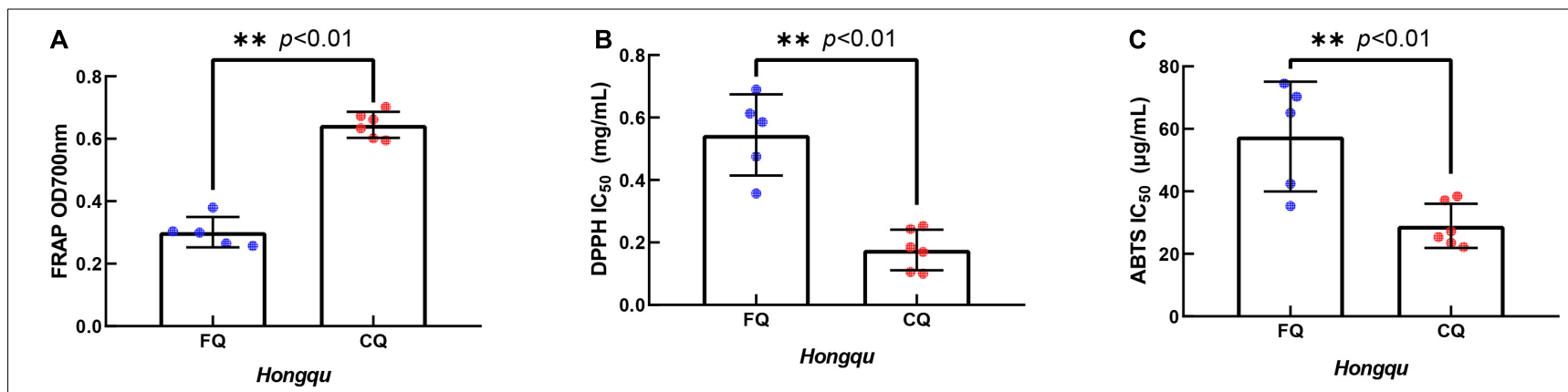

FIGURE 4 | In vitro antioxidant activity of extracts of functional $\mathrm{Qu}(\mathrm{FQ})$ and coloring $\mathrm{Qu}(\mathrm{CQ})$, respectively. (A) The ferric ion reducing antioxidant power of FQ and CQ. (B) The DPPH radical scavenging activity of FQ and CQ. (C) The ABTS radical scavenging activity of $F Q$ and $C Q$.

TABLE 3 | Correlation analysis among key active components and antioxidant activities of FQ and CQ.

\begin{tabular}{|c|c|c|c|c|c|c|c|c|}
\hline & $E_{505}$ & Ergosterol & MK & GABA & Polysaccharide & FRAP & DPPH & ABTS \\
\hline$E_{505}$ & 1.000 & -0.184 & -0.694 & -0.011 & -0.227 & $0.806^{\star \star}$ & $0.818^{\star \star}$ & $0.822^{\star \star}$ \\
\hline Ergosterol & & 1.000 & -0.600 & $0.811^{\star \star}$ & $0.945^{\star \star}$ & -0.182 & -0.427 & 0.009 \\
\hline MK & & & 1.000 & -0.872 & -0.500 & -0.700 & -0.200 & -0.500 \\
\hline GABA & & & & 1.000 & $0.779^{\star \star}$ & 0.123 & -0.046 & 0.241 \\
\hline Polysaccharide & & & & & 1.000 & -0.091 & -0.336 & 0.073 \\
\hline FRAP & & & & & & 1.000 & $0.791^{\star \star}$ & $0.918^{\star \star}$ \\
\hline DPPH & & & & & & & 1.000 & $0.782^{\star \star}$ \\
\hline ABTS & & & & & & & & 1.000 \\
\hline
\end{tabular}

The reciprocal of the half inhibition rate of DPPH and ABTS free radicals was used in correlation analysis.

“*** indicated that significantly correlated at the 0.01 level. 
TABLE 4 | Monascus pigments composition.

\begin{tabular}{|c|c|c|c|c|c|c|c|c|}
\hline No. & $\mathrm{Tr} / \mathrm{min}$ & Identification & Color & $\begin{array}{c}\text { Max } \\
\text { absorbance }\end{array}$ & Formula & Proposal ions & Experimental $\mathrm{m} / \mathrm{z}$ & References \\
\hline 1 & 43.81 & Monascorubrin & Orange & 472 & $\mathrm{C}_{23} \mathrm{H}_{26} \mathrm{O}_{5}$ & {$[\mathrm{M}+\mathrm{H}]^{+}$} & 383.1846 & Manchand et al., 1973 \\
\hline 2 & 36.68 & Monascin & Yellow & 386 & $\mathrm{C}_{21} \mathrm{H}_{26} \mathrm{O}_{5}$ & {$[\mathrm{M}+\mathrm{H}]^{+}$} & 359.1865 & $\begin{array}{c}\text { Chen et al., 1969; } \\
\text { Salomon and Karrer, } \\
1932\end{array}$ \\
\hline 3 & 35.39 & Monaphilone B & Yellow & 390 & $\mathrm{C}_{20} \mathrm{H}_{28} \mathrm{O}_{4}$ & {$[\mathrm{M}+\mathrm{H}]^{+}$} & 333.2049 & Hsu et al., 2010 \\
\hline 4 & 31.54 & Monascorubramine & Red & 529 & $\mathrm{C}_{23} \mathrm{H}_{27} \mathrm{NO}_{4}$ & {$[\mathrm{M}+\mathrm{H}]^{+}$} & 382.2000 & $\begin{array}{c}\text { Birch et al., 1962; } \\
\text { Sweeny et al., } 2012\end{array}$ \\
\hline 5 & 24.19 & Rubropunctamine & Red & 528 & $\mathrm{C}_{21} \mathrm{H}_{23} \mathrm{NO}_{4}$ & {$[\mathrm{M}+\mathrm{H}]^{+}$} & 354.1702 & $\begin{array}{c}\text { Birch et al., 1962; } \\
\text { Sweeny et al., } 2012\end{array}$ \\
\hline 6 & 37.01 & Rubropunctatin & Orange & 473 & $\mathrm{C}_{21} \mathrm{H}_{22} \mathrm{O}_{5}$ & {$[\mathrm{M}+\mathrm{H}]^{+}$} & 355.1538 & Chen et al., 1969 \\
\hline 7 & 43.18 & Ankaflavin & Yellow & 390 & $\mathrm{C}_{23} \mathrm{H}_{30} \mathrm{O}_{5}$ & {$[\mathrm{M}+\mathrm{H}]^{+}$} & 387.2168 & Manchand et al., 1973 \\
\hline 8 & 40.65 & Monasfluore B & Yellow & 390 & $\mathrm{C}_{23} \mathrm{H}_{28} \mathrm{O}_{5}$ & {$[\mathrm{M}+\mathrm{H}]^{+}$} & 385.2017 & Huang et al., 2008 \\
\hline 9 & 33.47 & Monasfluore A & Yellow & 386 & $\mathrm{C}_{21} \mathrm{H}_{24} \mathrm{O}_{5}$ & {$[\mathrm{M}+\mathrm{H}]^{+}$} & 357.1690 & Huang et al., 2008 \\
\hline 10 & 14.77 & FK17-P2B2 & Yellow & 390 & $\mathrm{C}_{13} \mathrm{H}_{16} \mathrm{O}_{4}$ & {$[\mathrm{M}+\mathrm{H}]^{+}$} & 237.1114 & $\begin{array}{l}\text { Jongrungruangchok } \\
\text { et al., } 2004\end{array}$ \\
\hline 11 & 22.59 & New red pigment & Red & 520 & $\mathrm{C}_{23} \mathrm{H}_{27} \mathrm{NO}_{5}$ & {$[\mathrm{M}+\mathrm{H}]^{+}$} & 398.1951 & Liang et al., 2019 \\
\hline 12 & 45.67 & Monapurfluore & Yellow & 390 & $\mathrm{C}_{23} \mathrm{H}_{32} \mathrm{O}_{4}$ & {$[\mathrm{M}+\mathrm{H}]^{+}$} & 373.2372 & Hsu et al., 2010 \\
\hline 13 & 43.17 & Monaphilone A & Yellow & 390 & $\mathrm{C}_{22} \mathrm{H}_{32} \mathrm{O}_{4}$ & {$[\mathrm{M}+\mathrm{H}]^{+}$} & 361.2372 & Hsu et al., 2010 \\
\hline 14 & 32.04 & Monascuspilion & Yellow & 390 & $\mathrm{C}_{21} \mathrm{H}_{28} \mathrm{O}_{5}$ & {$[\mathrm{M}+\mathrm{H}]^{+}$} & 361.2009 & Chiu et al., 2012 \\
\hline 15 & 22.19 & Red pigment & Red & 520 & $\mathrm{C}_{21} \mathrm{H}_{26} \mathrm{O}_{6}$ & {$[\mathrm{M}+\mathrm{H}]^{+}$} & 375.1797 & Liang et al., 2019 \\
\hline 16 & 23.38 & N-GABA-rubropunctatin & Red & 520 & $\mathrm{C}_{25} \mathrm{H}_{29} \mathrm{NO}_{6}$ & {$[\mathrm{M}+\mathrm{H}]^{+}$} & 440.2072 & Chen et al., 2017 \\
\hline 17 & 30.15 & Monarubrin & Yellow & 390 & $\mathrm{C}_{20} \mathrm{H}_{26} \mathrm{O}_{4}$ & {$[\mathrm{M}+\mathrm{H}]^{+}$} & 331.1901 & Loret and Morel, 2010 \\
\hline 18 & 49.44 & New yellow pigment & Yellow & 410 & $\mathrm{C}_{23} \mathrm{H}_{28} \mathrm{O}_{6}$ & {$[\mathrm{M}+\mathrm{H}]^{+}$} & 401.2349 & Chen et al., 2017 \\
\hline
\end{tabular}
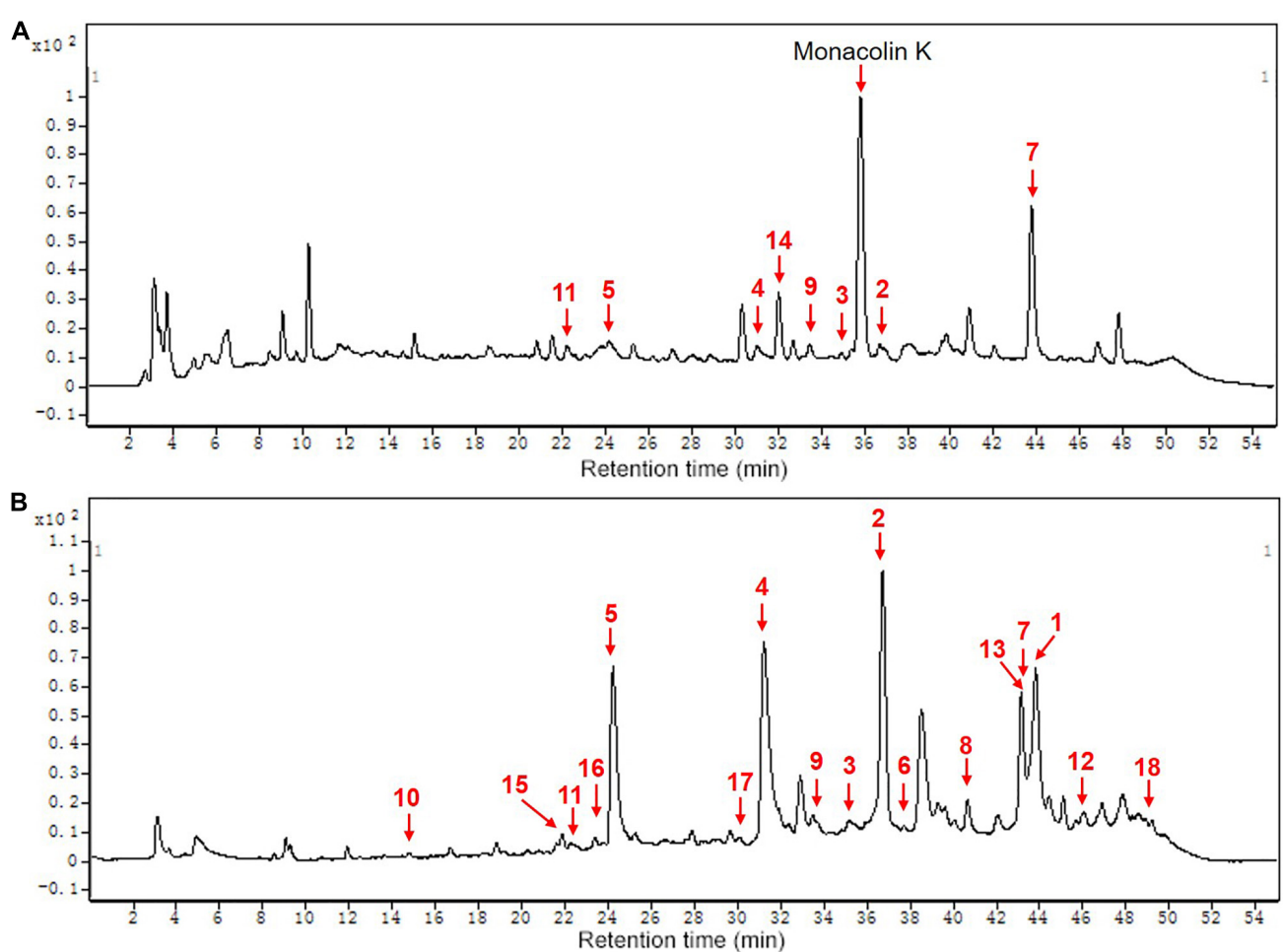

FIGURE 5 | The chemical composition of MPs of functional $Q u(F Q)$ and coloring $Q u(C Q)$, respectively. (A) functional $Q u(F Q)$. (B) Coloring $Q u(C Q) . ~ 1$, monascorubrin; 2, monascin; 3, monaphilone B; 4, monascorubramine; 5, rubropunctamine; 6, rubropunctatin; 7, ankaflavin; 8, monasfluore B; 9, monasfluore A; 10, FK17-P2B2; 11, new red pigment; 12, monapurfluore; 13, monaphilone A; 14, monascuspilion; 15, red pigment; 16, N-GABA-rubropunctatin; 17, monarubrin; 18 , new yellow pigment. 
The differences of MonAzPs may be the reason for their different antioxidant activities.

From the bioplot diagram (Figure 6A) and the HCA diagram (Figure 6D), FQ (green hexagon) and CQ (blue hexagon) were located on different sides of the $y$-axis or divided into different clusters, which indicates that FQ and CQ had significant differences. Red, orange, and yellow dots were used to represent red, orange, and yellow pigments, respectively. The smaller distance between Hongqu and MPs indicated that Hongqu played a more important role in MPs. CQ and most of the MPs were located on the right side of the $y$-axis, indicating that most of the MPs came from CQ. The distance between FQ and monascuspilion was smaller than that between CQ and monascuspilion, which meant monascuspilion mainly came from FQ. This was consistent with the results in Figure 5. According to the permutation test diagram of the OPLS-DA model (Figure 6B), it can be seen that the OPLS-DA model was effective and not overfit $\left(R^{2}>0.4\right)$. According to the VIP diagram (Figure 6C), there were nine different MPs with a significant difference between FQ and CQ (Supplementary Table 1, VIP > 1), including monascuspilion, ankaflavin, monaphilone A, monascin, new red pigment, monarubrin, monascorubramine, and new yellow pigment.

\section{Antioxidant Activity of MYPs Antioxidant Activity of MYPs in vitro}

The antioxidant activities of seven MYPs were evaluated by antioxidant assay in vitro, including the $\mathrm{DPPH}$ free radical scavenging rate (Figure 7A), superoxide anion clearance rate (Figure 7B), and inhibition rate of peroxidation of yolk lipoprotein (Figure 7C). The three chemical assays reveal the different antioxidant characteristics of MYPs based on different antioxidant mechanisms. The antioxidant capacity
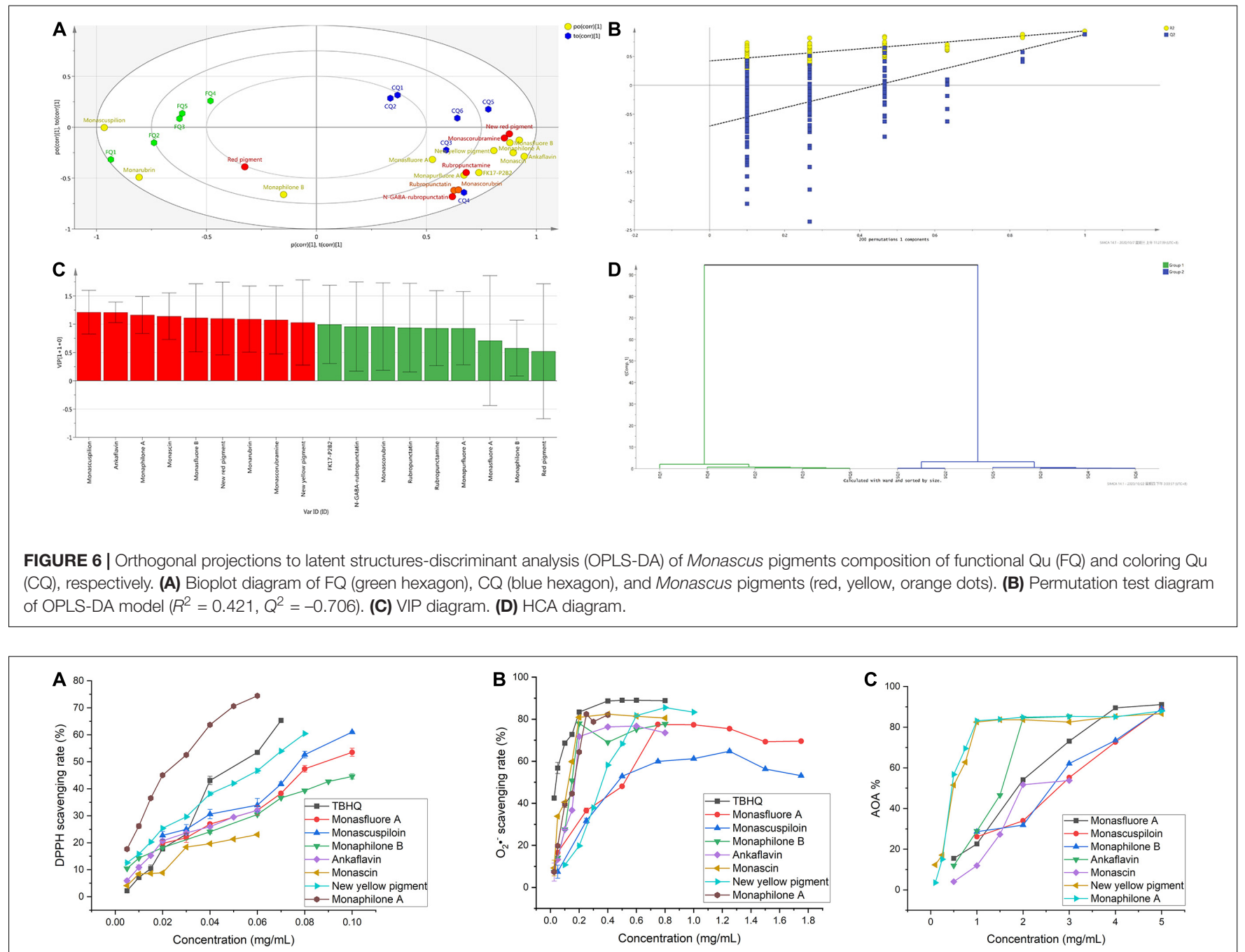

FIGURE 7 | In vitro antioxidant of yellow pigments purified from functional Qu (FQ) and coloring Qu (CQ). (A) The DPPH radical scavenging activity of yellow pigment from FQ and CQ. (B) The superoxide anion radical scavenging activity of yellow pigment from FQ and CQ. (C) The inhibition rate of yolk lipoprotein peroxidation of yellow pigment from $F Q$ and $C Q$. 
of MYPs increased with the increase of concentration. The antioxidant activities of MYP were similar in the three chemical antioxidant assays. Chemical antioxidant tests revealed that the antioxidant activities of monaphilone A, ankaflavin, and new yellow pigment only separated from CQ were significantly stronger than monasfluore $\mathrm{A}$ and monascuspilion only separated from FQ. For example, the $\mathrm{IC}_{50}$ of the new yellow pigment in three chemical assays (0.062, 0.376, and $0.580 \mathrm{mg} / \mathrm{ml})$ was smaller than that of monascuspiloin $(0.080$, 0.548 , and $2.670 \mathrm{mg} / \mathrm{ml}$ ). This might be the main reason for the significantly stronger antioxidant capacity of the crude ethanol extract of CQ than FQ. MYPs have good DPPH radical scavenging ability and superoxide anion scavenging capacity, and bad vitellin inhibitory capacity. The $\mathrm{IC}_{50}$ of the DPPH free radical scavenging rate of MYPs from FQ (0.080-0.091 $\mathrm{mg} / \mathrm{ml}$ ) was smaller than the $\mathrm{IC}_{50}$ of crude ethanol extracts of FQ $(0.544 \mathrm{mg} / \mathrm{ml})$. The results indicated that the antioxidant activity of yellow pigments was improved significantly after purification.

\section{Cellular Antioxidant Activity of MYPs}

Compared with the antioxidant assay in vitro and animal experiments, the evaluation of antioxidant activity by cell model test was more economical and faster. It is widely used to quantify the cellular antioxidant activity (CAA) of phytochemicals, food extracts, and nutritional supplements. Therefore, we consider CAA assays as reliable and sensitive methods for antioxidative activity evaluation. With quercetin as a positive control, CAA of seven pigments was evaluated with an oxidative damage model of human colon adenocarcinoma Caco- 2 cells induced by AAPH (Kellett et al., 2018). The CAA value of MYPs at the $20 \mu \mathrm{g} / \mathrm{ml}$ concentration showed that the new yellow pigment (65.46 units) had the best antioxidant activity, followed by monasfluore A (42.15 units) and monaphilone B (39.19 units), which were all significantly better than monascin (26.86 units) and ankaflavin (22.19 units), the two most frequently reported MYPs (Figure 8A). The antioxidant capacity of the natural product was usually converted to an equivalent concentration of quercetin based on its CAA values for making the result more
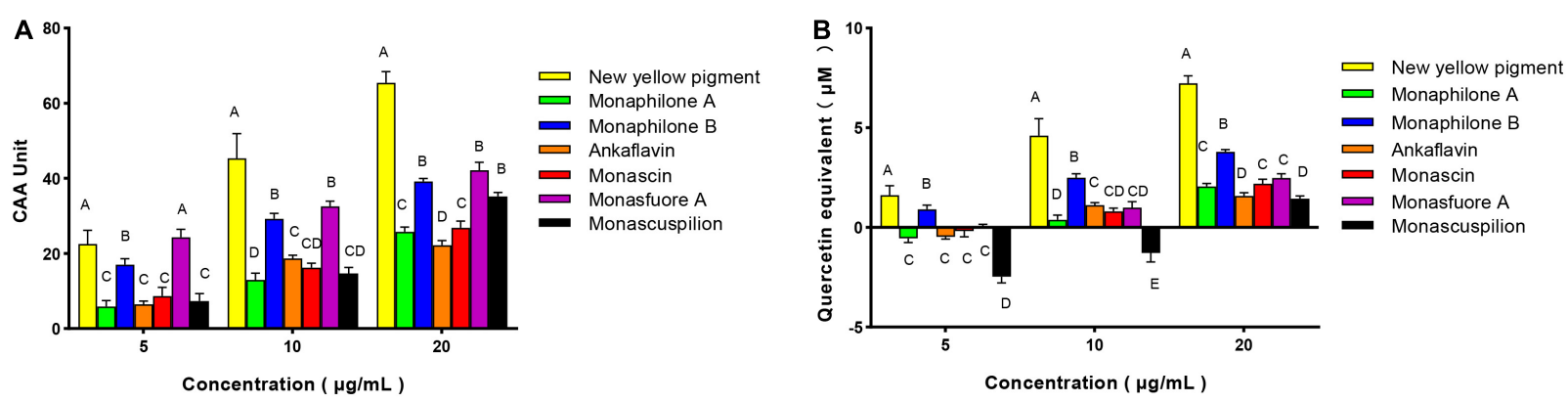

FIGURE 8 | Cellular antioxidant activity (CAA) of Monascus yellow pigment from functional Qu (FQ) and coloring Qu (CQ) and quercetin equivalent in Caco-2 cells. (A) Cellular antioxidant activity value. (B) Quercetin equivalent.

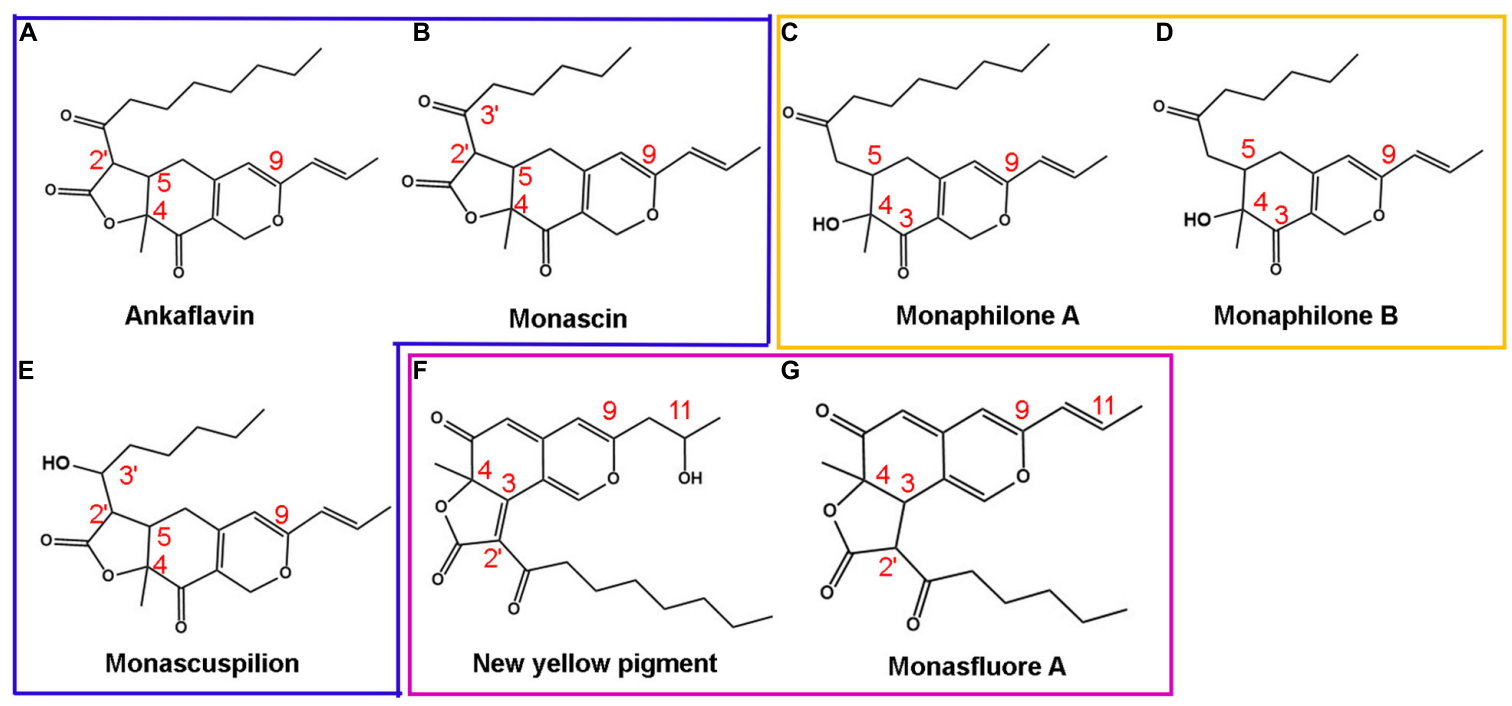

FIGURE 9 | Structures of Monascus yellow pigments. (A) ankaflavin, (B) monascin, (C) monaphilone A, (D) monaphilone B, (E) monascuspilion, (F) new yellow pigment, and (G) monasfluore A. Similar structures are represented by different colored boxes. Monascus yellow pigments (MYPs) in the blue box have a C5-C2' linear tricyclic carbon skeleton, MYPs in the orange box do not have a lactone ring, and MYPs in the purple box have a C3-C2' angular tricyclic carbon skeleton. 
comparable (Zhou et al., 2020). The quercetin equivalent of MYPs was shown in Figure 8B. The quercetin equivalent of the new yellow pigment was $7.23 \mu \mathrm{M}$. In short, the new yellow pigment had outstanding antioxidant capacity in vitro, and its antioxidant capacity in vivo was worthy of in-depth study.

With the help of in vitro and in vivo antioxidant experiments, the relationship between the structure and antioxidant activity was further investigated. Based on the structure of 111 identified single pigment, the tricyclic carbon skeleton structure or the dicyclic carbon skeleton was the core structure of MonAzPs, which generally contained one to three carbonyl groups and two to five unsaturated double bonds. To date, a unitary trunk pathway had been revealed to produce four classical pigments and intermediates. All other 106 species MonAzPs were generated by various shunt pathways branching off from the trunk pathway (Chen et al., 2019). First, the alterations in the position and number of hydroxyl groups affect the antioxidant activity. The hydroxyl group of C-4 was prone to condensation reaction to form a lactone ring $\mathrm{C} 5-\mathrm{C} 2$ ' condensation and cyclization formed a $\mathrm{C} 5-\mathrm{C} 2{ }^{\prime}$ linear tricyclic carbon skeleton or $\mathrm{C} 3-\mathrm{C}_{2}^{\prime}$ condensation and cyclization formed a $\mathrm{C} 3-\mathrm{C} 2$ ' angle tricyclic carbon skeleton. The seven yellow pigments could be divided into three categories according to carbon skeleton characteristics and the CAA. New yellow pigment and monasfluore A (Figures 9F,G) had an angular tricyclic carbon skeleton, obviously different from the linear tricyclic core of classical monascin, ankaflavin, and monascuspilion (Figures 9A,B,E). It is worth noting that the antioxidant activity of the new yellow pigment and monasfluore A was stronger and that of monascin, ankaflavin, and monascuspilion. Monaphilone A and monaphilone B had moderate antioxidant activity lacking the $\gamma$-lactone ring (instead of a C-4 hydroxyl group) (Figures 9C,D). First of all, alterations of the hydroxyl group of MYPs affect the antioxidant activities significantly. The results showed that the new yellow pigment with a hydroxyl group on $\mathrm{C}-11$ possessed much higher antioxidant activities than monasfluore A and the others with a C10 (11) double bond on C-11. Monascuspilion with a hydroxyl group on C$3^{\prime}$ brought higher antioxidant activities than monascin with a ketone group on C-3'. In the case of MYPs, alterations of the $\gamma$-lactone ring and alkyl side chain could affect the antioxidant activities slightly. Monaphilone A and monaphilone $\mathrm{B}$ (lacking $\gamma$-lactone ring) possessed higher antioxidant activity than ankaflavin and monascin (linear tricyclic core), respectively. Moreover, monaphilone $\mathrm{B}$ and monascin $\left(\mathrm{R}=\mathrm{C}_{5} \mathrm{H}_{11}\right)$ had higher antioxidant activities than monaphilone $\mathrm{A}$ and ankaflavin $\left(R=\mathrm{C}_{7} \mathrm{H}_{15}\right)$. In short, the alterations that occurred at $\mathrm{C}$ $3^{\prime}, \mathrm{C}-11$, and the carbon skeleton more obviously affected the antioxidant activities.

The inhibitory effects of azaphilonoid pigments on 12O-tetradecanoylphorbol-13-acetate (TPA)-induced ear edema were much stronger than those of non-azaphilonoid pigments (Akihisa et al., 2005). The critical structures that enhance the anti-inflammatory activity of Monascus yellow and orange pigments were found by Hsu (Hsu L. C. et al., 2013), and the structure-activity relationship was consistent with the results of the relationship between the structure and antioxidant activity of MYPs in this article. Because inflammation is a kind of exogenous stress, the Keap1-Nrf2/ARE antioxidant signal pathway is often activated (Lee B. H. et al., 2013). Nrf2 is an important transcription factor that regulates cell protection mechanisms such as antioxidant and anti-inflammatory activities (Pall and Levine, 2015). Therefore, anti-inflammatory activity is closely related to antioxidant activity. It is worth noting that MonAzPs with hydroxyl groups on C-3', C-11 had significantly stronger antioxidant activity than a ketone group and C10 (11) double bond on C- $3^{\prime}$, C-11, respectively. The previous studies had reported that the antioxidant potential of MYPs could easily transfer hydrogen to and accept electrons from free radicals through HAT and SET mechanisms. This result was consistent with the alterations of key antioxidant structures of MYPs.

\section{CONCLUSION}

This study analyzes the difference of key active components from two types of Hongqu (FQ and CQ). It found that MonAzPs may play an essential role in the antioxidant activity. The antioxidant activities of monaphilone A, ankaflavin, and new yellow pigment only from CQ are significantly more potent than monasfluore A and monascuspilion only from FQ. The new yellow pigment has the best antioxidant activity, whereas monascin and ankaflavin, the two most frequently reported MYPs, have the worst antioxidant activity. MYPs with hydroxyl groups on C-3' and $\mathrm{C}-11$ are proved to displace higher antioxidant activity than MYPs with a ketone group or C10 (11) double bond on C-3' and $\mathrm{C}-11$. Thus, it provides a potential antioxidant resource for functional foods. Future studies should focus on the antioxidant activities in vivo and the potential mechanism to better elucidate the antioxidant mechanisms via hydrogen atom transfer and single electron transfer.

\section{DATA AVAILABILITY STATEMENT}

The raw data supporting the conclusions of this article will be made available by the authors, without undue reservation.

\section{AUTHOR CONTRIBUTIONS}

LW performed the research and wrote the manuscript. $\mathrm{KZ}$ and FC participated in collecting raw materials and analyzing the metabolites. GC and YY calculated and analyzed the data. XL, WZ, PR, and LN designed the study. All authors reviewed and approved the final version of the manuscript.

\section{FUNDING}

This research project was financed by the National Key R\&D Program of China (grant no. 2018YFC1604106), UniversityIndustry Cooperation Project of the Science and Technology Department of Fujian Province (grant no. 2019N5002), and the National Natural Science Foundation of China (grant no. 32072204). 


\section{ACKNOWLEDGMENTS}

We would like to thank Huiqin Wang of Zhejiang Gongshang University for testing the cellular antioxidant activity.

\section{REFERENCES}

Akihisa, T., Tokuda, H., Yasukawa, K., Ukiya, M., Kiyota, A., Sakamoto, N., et al. (2005). Azaphilones, furanoisophthalides, and amino acids from the extracts of Monascus pilosus-fermented rice (red-mold rice) and their chemopreventive effects. J. Agric. Food Chem. 53, 562-565. doi: 10.1021/jf040199p

Birch, A. J., Cassera, A., Fitton, P., Holker, J. S. E., Smith, H., Thompson, G. A., et al. (1962). 699. Studies in relation to biosynthesis. part XXX. Rotiorin, monascin, and rubropunctatin. J. Chem. Soc. 3583-3586. doi: 10.1039/jr9620003583

Brand Williams, W., Cuvelier, M. E., and Berset, C. (1995). Use of a free radical method to evaluate antioxidant activity. LWT Food Sci. Technol. 28, 25-30. doi: 10.1016/s0023-6438(95)80008-5

Chen, C. L., Chang, K. Y., and Pan, T. M. (2015). Monascus purpureus NTU 568 fermented product improves memory and learning ability in rats with aluminium-induced Alzheimer's disease. J. Funct. Foods 21, 167-177. doi: 10.1016/j.jff.2015.12.017

Chen, F. C., Manchard, P. S., and Whalley, W. B. (1969). The structure of monascin. J. Chem. Soc. D Chem. Commun. 21, 130-131. doi: 10.1039/c29690000130

Chen, W., Chen, R., Liu, Q., He, Y., He, K., Ding, X., et al. (2017). Orange, red, yellow: biosynthesis of azaphilone pigments in Monascus fungi. Chem. Sci. 8, 4917-4925. doi: 10.1039/c7sc00475c

Chen, W., Feng, Y., Molnar, I., and Chen, F. (2019). Nature and nurture: confluence of pathway determinism with metabolic and chemical serendipity diversifies Monascus azaphilone pigments. Nat. Prod. Rep. 36, 561-572. doi: 10.1039/ c8np00060c

Chiu, H. W., Fang, W. H., Chen, Y. L., Wu, M. D., Yuan, G. F., Ho, S. Y., et al. (2012). Monascuspiloin enhances the radiation sensitivity of human prostate cancer cells by stimulating endoplasmic reticulum stress and inducing autophagy. PLoS One 7:e40462. doi: 10.1371/journal.pone.0040462

Dubois, M., Gilles, K. A., Hamilton, J. K., Rebers, P. A., and Smith, F. (1956). Colorimetric method for determination of sugars and related substances. Anal. Chem. 28, 350-356. doi: 10.1021/ac60111a017

Eda, M., Kuda, T., Kataoka, M., Takahashi, H., and Kimura, B. (2016). Antiglycation properties of the aqueous extract solutions of dried algae products harvested and made in the Miura Peninsula, Japan, and effect of lactic acid fermentation on the properties. J. Appl. Phycol. 28, 3617-3624. doi: 10.1007/ s10811-016-0891-7

Garzón, A. G., Van de Velde, F., and Drago, S. R. (2020). Gastrointestinal and colonic in vitro bioaccessibility of $\gamma$-aminobutiric acid (GABA) and phenolic compounds from novel fermented sorghum food. LWT 130:109664. doi: 10. 1016/j.lwt.2020.109664

Guan, W., Zhang, J., Yan, R., Shao, S., Zhou, T., Lei, J., et al. (2016). Effects of UV-C treatment and cold storage on ergosterol and vitamin D2 contents in different parts of white and brown mushroom (Agaricus bisporus). Food Chem. 210, 129-134. doi: 10.1016/j.foodchem.2016.04.023

Gum, S. I., Nguyen, P. A., Lee, J. R., Han, Y. H., and Cho, M. K. (2017). The physico-chemical alteration of lovastatin and enhanced antioxidant effect of Bacillus subtilis fermented-red yeast rice product. Food Chem. 232, 203-209. doi: 10.1016/j.foodchem.2017.04.023

Hsu, L. C., Liang, Y. H., Hsu, Y. W., Kuo, Y. H., and Pan, T. M. (2013). Anti-inflammatory properties of yellow and orange pigments from Monascus purpureus NTU 568. J. Agric. Food Chem. 61, 2796-2802.

Hsu, W. H., Lee, B. H., Li, C. H., Hsu, Y. W., and Pan, T. M. (2013). Monascin and AITC attenuate methylglyoxal-induced PPAR $\gamma$ phosphorylation and degradation through inhibition of the oxidative stress/PKC pathway depending on Nrf2 activation. J. Agric. Food Chem. 61, 5996-6006. doi: 10.1021/jf401197r

Hsu, Y. W., Hsu, L. C., Liang, Y. H., Kuo, Y. H., and Pan, T. M. (2010). Monaphilones A-C, three new antiproliferative azaphilone derivatives from Monascus purpureus NTU 568. J. Agric. Food Chem. 58, 8211-8216. doi: 10. 1021/jf100930j

\section{SUPPLEMENTARY MATERIAL}

The Supplementary Material for this article can be found online at: https://www.frontiersin.org/articles/10.3389/fmicb. 2021.715295/full\#supplementary-material

Huang, C. F., Shen, S. M., Chen, W. T., and Chen, C. C. (2019). The effects of mutation and temperature variation on monacolin $\mathrm{K}$ production by monascus sp. and relative statistical parameter analysis of monacolin $\mathrm{K}$ production. Phytochem. Lett. 32, 143-150. doi: 10.1016/j.phytol.2019.05.011

Huang, Q., Zhang, H., and Xue, D. (2017). Enhancement of antioxidant activity of Radix Puerariae and red yeast rice by mixed fermentation with Monascus purpureus. Food Chem. 226, 89-94. doi: 10.1016/j.foodchem.2017.01.021

Huang, Z., Guo, W., Zhou, W., Li, L., Xu, J., Hong, J. L., et al. (2019). Microbial communities and volatile metabolites in different traditional fermentation starters used for Hong Qu glutinous rice wine. Food Res. Int. 121, 593-603. doi: 10.1016/j.foodres.2018.12.024

Huang, Z., Xu, Y., Li, L., and Li, Y. (2008). Two new monascus metabolites with strong blue fluorescence isolated from red yeast rice. J. Agric. Food Chem. 56, 112-118. doi: 10.1021/jf072985a

Jongrungruangchok, S., Kittakoop, P., Yongsmith, B., Bavovada, R., Tanasupawat, S., Lartpornmatulee, N., et al. (2004). Azaphilone pigments from a yellow mutant of the fungus Monascus kaoliang. Phytochemistry 65, 2569-2575. doi: 10.1016/j.phytochem.2004.08.032

Kellett, M. E., Greenspan, P., and Pegg, R. B. (2018). Modification of the cellular antioxidant activity (CAA) assay to study phenolic antioxidants in a Caco-2 cell line. Food Chem. 244, 359-363. doi: 10.1016/j.foodchem.2017. 10.035

Lee, B. H., Hsu, W. H., Huang, T., Chang, Y. Y., Hsu, Y. W., and Pan, T. M. (2013). Effects of monascin on anti-inflammation mediated by $\mathrm{Nrf} 2$ activation in advanced glycation end product-treated THP-1 monocytes and methylglyoxaltreated wistar rats. J. Agric. Food Chem. 61, 1288-1298. doi: 10.1021/jf305067n

Lee, C. L., and Pan, T. M. (2012). Development of Monascus fermentation technology for high hypolipidemic effect. Appl. Microbiol. Biotechnol. 94, 14491459. doi: 10.1007/s00253-012-4083-3

Lee, C. L., Hung, Y. P., Hsu, Y. W., and Pan, T. M. (2013). Monascin and ankaflavin have more anti-atherosclerosis effect and less side effect involving increasing creatinine phosphokinase activity than monacolin $\mathrm{K}$ under the same dosages. J. Agric. Food Chem. 61, 143-150. doi: 10.1021/jf304346r

Lee, D. E., Shin, G. R., Lee, S., Jang, E. S., Shin, H. W., Moon, B. S., et al. (2016). Metabolomics reveal that amino acids are the main contributors to antioxidant activity in wheat and rice gochujangs (Korean fermented red pepper paste). Food Res. Int. 87, 10-17. doi: 10.1016/j.foodres.2016.06.015

Liang, J. X., Zhang, Q. Q., Huang, Y. F., Pang, H. Q., Liu, X. G., Gao, W., et al. (2019). Comprehensive chemical profiling of monascusfermented rice product and screening of lipid-lowering compounds other than monacolins. J. Ethnopharmacol. 238:111879. doi: 10.1016/j.jep.2019. 111879

Loret, M. O., and Morel, S. (2010). Isolation and structural characterization of two new metabolites from monascus. J. Agric. Food Chem. 58, 1800-1803. doi: 10.1021/jf903231p

Lu, Q. Y., Lee, R. P., Huang, J., Yang, J., Henning, S. M., Hong, X., et al. (2015). Quantification of bioactive constituents and antioxidant activity of Chinese yellow wine. J. Food Composit. Anal. 44, 86-92. doi: 10.1016/j.jfca.2015. 07.005

Manchand, P. S., Whalley, W. B., and Chen, F. (1973). Isolation and structure of ankaflavin: a new pigment from Monascus anka. Phytochemistry 12, 2531-2532. doi: 10.1016/0031-9422(73)80470-4

Ministry of Industry and Information Technology of the People's Republic of China (2013). Light Industry Standard the People's Republic of China QB/T 4587-2013, Gamma-Aminobutyric acid. Beijing: Ministry of Industry and Information Technology

Mirzadeh, M., Arianejad, M. R., and Khedmat, L. (2020). Antioxidant, antiradical, and antimicrobial activities of polysaccharides obtained by microwave-assisted extraction method: a review. Carbohydr. Polym. 229:115421. doi: 10.1016/j. carbpol.2019.115421 
National Development and Reform Commission of the People's Republic of China (2007). Light Industry Standard of the People's Republic of China QB/T 28472007, Functional Red Kojic Rice (Powder). Beijing: National Development and Reform Commission.

National Health and Family Planning Commission of the People's Republic of China (2015). National Standard of the people's Republic of China GB 1886.192015. Food Safety National Standard Food Additives. Beijing: National Health and Family Planning Commission.

Pall, M. L., and Levine, S. (2015). Nrf2, a master regulator of detoxification and also antioxidant, anti- inflammatory and other cytoprotective mechanisms, is raised by health promoting factors. Acta Physiol. Sin. 67, 1-18.

Qu, J., Wang, B., Wu, J. J., Xu, C., Zhu, S. M., and Chen, F. S. (2008). Study on separation of monascus pigment and their antioxidative properties. Modern Food Sci. Technol. 24, 527-531.

Salomon, H., and Karrer, P. (1932). Pflanzenfarbstoffe XXXVIII. Ein Farbstoff aus „rotem” Reis, Monascin. Helvetica Chim. Acta 15, 18-22.

Shi, Y. C., Liao, V. H.-C., and Pan, T.-M. (2012). Monascin from red mold dioscorea as a novel antidiabetic and antioxidative stress agent in rats and Caenorhabditis elegans. Free Radic. Biol. Med. 52, 109-117. doi: 10.1016/j. freeradbiomed.2011.09.034

Srianta, I., Zubaidah, E., Estiasih, T., Yamada, M., and Harijono. (2016). Comparison of Monascus purpureus growth, pigment production and composition on different cereal substrates with solid state fermentation. Biocatal. Agric. Biotechnol. 7, 181-186. doi: 10.1016/j.bcab.2016.05.011

Sridhar, K., and Charles, A. L. (2019). In vitro antioxidant activity of Kyoho grape extracts in DPPH and ABTS assays: estimation methods for EC50 using advanced statistical programs. Food Chem. 275, 41-49 doi: 10.1016/j.foodchem. 2018.09.040

Sweeny, J. G., Estrada-Valdes, M. C., Iacobucci, G. A., Sato, H., and Sakamura, S. (2012). Photoprotection of the red pigments of Monascus anka in aqueous media by 1,4,6-trihydroxynaphthalene. J. Agricult. Food Chem. 29, 1189-1193. doi: $10.1021 /$ jf00108a023

Takei, M., Kuda, T., Eda, M., Shikano, A., Takahashi, H., and Kimura, B. (2017). Antioxidant and fermentation properties of aqueous solutions of dried algal products from the Boso Peninsula, Japan. Food Biosci. 19, 85-91. doi: 10.1016/ j.fbio.2017.06.006

Wang, J. J., and Pan, T. M. (2003). Effect of red mold rice supplements on serum and egg yolk cholesterol levels of laying hens. J. Agric. Food Chem. 51, 4824-4829. doi: $10.1021 / \mathrm{jf} 034296 \mathrm{e}$
Wolfe, K. L., and Liu, R. H. (2007). Cellular antioxidant activity (CAA) assay for assessing antioxidants, foods, and dietary supplements. J. Agric. Food Chem. 55, 8896-8907. doi: 10.1021/jf0715166

Wu, L., Shen, H. S., Tang, B. S., Yang, Y. L., and Chen, J. C. (2016). Effects of Canellia oleifera abel extraction on enhancing mycelial metabolism for compounds with Agrocybe chaxingu Huang and antioxidant function. J. Chinese Institute Food Sci. Technol. 16, 59-64.

Xie, J. H., Shen, M. Y., Xie, M. Y., Nie, S. P., Chen, Y., Li, C., et al. (2012). Ultrasonicassisted extraction, antimicrobial and antioxidant activities of Cyclocarya paliurus (Batal.) Iljinskaja polysaccharides. Carbohydr. Polym. 89, 177-184. doi: 10.1016/j.carbpol.2012.02.068

Zhang, X., Liu, C., Tian, W., Zhang, H., and Li, P. (2020). Theoretical and experimental investigation of the antioxidative activity of monascin. Food Funct. 11, 5915-5923. doi: 10.1039/c9fo02410g

Zhou, J., Gao, G., Zhang, S., Wang, H., Ke, L., Zhou, J., et al. (2020). Influences of calcium and magnesium ions on cellular antioxidant activity (CAA) determination - ScienceDirect. Food Chem. 320, 1-7.

Zhou, W., Guo, R., Guo, W., Hong, J., and Li, L. (2019). Monascus yellow, red and orange pigments from red yeast rice ameliorate lipid metabolic disorders and gut microbiota dysbiosis in Wistar rats fed on a high-fat diet. Food Funct. 10, 1073-1084. doi: 10.1039/c8fo02192a

Conflict of Interest: The authors declare that the research was conducted in the absence of any commercial or financial relationships that could be construed as a potential conflict of interest.

Publisher's Note: All claims expressed in this article are solely those of the authors and do not necessarily represent those of their affiliated organizations, or those of the publisher, the editors and the reviewers. Any product that may be evaluated in this article, or claim that may be made by its manufacturer, is not guaranteed or endorsed by the publisher.

Copyright (c) $2021 \mathrm{Wu}$, Zhou, Chen, Chen, Yu, Lv, Zhang, Rao and Ni. This is an open-access article distributed under the terms of the Creative Commons Attribution License (CC BY). The use, distribution or reproduction in other forums is permitted, provided the original author(s) and the copyright owner(s) are credited and that the original publication in this journal is cited, in accordance with accepted academic practice. No use, distribution or reproduction is permitted which does not comply with these terms. 